Mother and son presented as suspicious and hostile. They shared the delusion that people wanted to harm them and that there was a plot to remove the son from the home. They both demonstrated a fear of eating in public as they believed the food would be poisoned. It was concluded that until the two could be separated, Mr X's mental state would not improve. Eventually the patient began attending a day centre. He remained suspicious and failed to engage. He was observed to be extremely restless. He was finally persuaded to have thyroid function tests.

In conjunction with the physical findings, the results revealed $\mathrm{Mr} \mathrm{X}$ to be in thyrotoxic crisis. $\mathrm{T} 4=89.4(\mathrm{n} 10-29), \mathrm{T} 3=35.0(\mathrm{n} 4.4-8.8), \mathrm{TSH}=<0.1$ (n $0.3-4.0$ )

The chest $\mathrm{x}$-ray revealed massive cardiomegaly.

$\mathrm{Mr} \mathrm{X}$ responded well to standard treatment of thyrotoxic crisis. Lasègue \& Falret were the first to describe folie à deux in 1877. They reported that "In folie à deux, one individual is the active element; being more intelligent than the other he creates the delusion and gradually imposes it upon the second or passive one". In the case presented it appears that both $\mathrm{Mr} \mathrm{X}$ and his mother were psychotic as a result of thyroid disorder; many of the delusions were then shared. The mother being more intelligent, initially appeared to be creating the delusions for her "passive" son (induced psychosis), however once the diagnosis of thyroid disorder in the son was made, it became apparent that this was a case of folie simultanée, and not folie à deux. It may therefore be advisable, to ensure that both members of an apparent folie à deux, within a family have their thyroid status checked. Are readers aware whether this has been reported previously?

JeANnette Phillips

The Maudsley Hospital

London SE5 $8 A Z$

Reference

LASEgGUe, D. \& FALRET, J. (1877) La folie à deux ou folie communique. Translation of the original paper in American Journal of Psychiatry. October 1964, Supplement 121 .

\section{Psychiatric disorder and firearm ownership}

DEAR Sirs

Mr C.M., a 37-year-old divorced man whose father had been diagnosed as suffering from Huntington's Chorea three years earlier was referred for an opinion as to the appropriateness of his possession of a gun licence (for his shot-gun). He had been the only family member to take up the offer of presymptomatic testing and had been told he had a $95 \%$ risk of developing the disorder. He was at the time of assessment not exhibiting any abnormality of movement nor was any evidence of psychiatric disorder noted or complained of. He had been a regular gun user since his teens and stated his willingness both to cooperate fully with any followup recommended and to give up his gun at the first signs of illness. He was, however, extremely reluctant to consider giving up his gun until such signs appeared as it was his life's "only pleasure".

The case was discussed at a hospital case conference and it was noted that applicants for firearm licences had to disclose any criminal or psychiatric history they might have to the police, who supply such licences. In this case the patient had not as yet done so and both the patient's general practitioner and clinical geneticist had considered breaching medical confidentiality and informing the relevant authority. Such a breach was discussed at the case conference and felt to be an unfortunate, and potentially problematic, start to what was likely to be a long-term relationship between the patient and psychiatric services. The BMA's 'Firearms Guidance Notes' were found to recommend that if doctors "have reason to believe that an individual has access to firearms and is currently a danger to themselves or to society they should be prepared to breach confidence and inform the appropriate authorities (in this case the Chief Constable)". As in this case the patient was not considered to be dangerous currently, the consensus of the case conference was that it was not appropriate to breach confidentiality. The patient remains under regular follow-up, and his possession of a firearm under constant review. I would welcome readers' opinions on this situation or descriptions of similar problems relating to concurrence of psychiatric disorder and firearm ownership.

Barnsley Hall Hospital

Gary HOSTY

\section{Bromsgrove}

West Midlands

\section{Statistical methods in audit}

\section{Dear Sirs}

Medical audit is seen as distinct from research in its purpose and its methods. We would like to make a report illustrating that the interpretation of audit data must be governed by the principles of statistics.

In our unit we observed an increase in the use of section 5(2) during a certain month when eight sections were applied. In the preceding six months the average rate had been 3.25 . An audit was conducted regarding this "epidemic" but, applying a $\chi^{2}$ test to the data set indicated that it could have been a chance finding $(P=0.25)$. Thus there was not necessarily an increase in the use of the section to form the basis for audit. 
Audit cannot therefore be considered immune from the principles that govern research. Small data sets and many audits of limited size are especially vulnerable in this respect.

Queen Elizabeth II Hospital

Welwyn Garden City

Hertfordshire $A L 74 H Q$

\section{Feminism and psychiatry}

DeAr Sirs

We found it difficult to understand why Dr Charlton (Psychiatric Bulletin, 1992, 16, 769-779) views feminism as damaging to psychiatry. He does not seem to want to listen to what women and men who consider psychiatry from a feminist stand-point have to say. He produces no evidence that feminists are only interested in the single issue of gender.

Our argument is about the importance of gender. Dr Charlton mentions the recent supplement of The British Journal of Psychiatry 'Women in Mental Health' as an example of feminism invading psychiatry. In our view the supplement is not feminist enough. While we welcome the focus on women's mental health, the supplement failed in its analysis of gender-power relations, central to feminist perspectives on science and clinical practice. This collection of papers on the whole remained faithful to the tradition of treating women as the objects of scrutiny and treatment rather than taking women's experience as a starting point.

The election of the first woman President of the Royal College of Psychiatrists may provide an opportunity to make real progress on gender issues within psychiatry.

It is a pity that Dr Charlton uses science to reduce feminism particularly in view of his own concern about the value of science in psychiatry (e.g. Charlton, 1990). Clinical practice in psychiatry can only be improved by attention to sexual discrimination.

D. B. DOUBLE

Royal Hallamshire Hospital

P. NICOLSON

Sheffield S10 $2 \mathrm{JF}$

Reference

Charlton, B. G. (1990) A critique of biological psychiatry.

Psychological Medicine, 20, 3-6.

Reply

DeAR SIRS

Thanks to the authors for responding to my provocative polemic. In fairness, I do listen to what those who consider psychiatry from a feminist stand-point have to say. It is because I listen that I am worried. I have suggested a plausible definition of feminism (as opposed to a merely proper and moral attitude to the issue of gender) - feminism is a way of life rather than a part of life (otherwise why define oneself by the label "feminist"?).

Feminism is just one way of analysing society by chromosome analysis, as it were (or perhaps by socially-constructed gender). Other ways are by class (Marxism), by ethnic group (anti-racism), or by conformity to an economic ideal (libertarian freemarket-ism). All of these are useful and valid; none are dominant. None even begin to capture the richness and complexity of human life. All are reductionistic and leave out much of what I value in human society.

So, there is no argument that gender is important, in both positive and negative ways. But it is not supreme, and in psychiatry it ought not to be supreme. As for the analysis of gender-power relations ... yes, I've read Michel Foucault too, But power/knowledge analysis isn't medicine and it isn't science. It is sociology, history, genealogical philosophy - lots of other things but not psychiatry. It isn't only the British Journal of Psychiatry supplement which treats women (why just "women"-surely men too?) as "the objects of scrutiny and treatment rather than taking women's experience as a starting point"; no, this is just what science and medicine do. And if they did not, they would not be science and medicine. Taking women's experience as a starting point is something else altogether.

So I was right: feminist views do put feminism as a higher priority than medicine or science as we know them. Feminists wish to scrap psychiatry and rebuild it anew, presumably using gender-power analysis as a guide. Is this not exactly the "threat of single-issue politics" to which I alluded in my article?

Feminists cannot have it both ways. Either they want radically to "reform" psychiatry (which is obviously a threat to psychiatry), or they don't want to.

\section{Bruce G. Charlto \\ of Epidemiology and Public Health}

Are psychiatric case-notes offensive?

DEAR SIRS

Speaking from a user's point of view, I would like to respond to the article 'Are psychiatric case-notes offensive?' (Psychiatric Bulletin, 1992, 16, 675-677). I was delighted to find professionals prepared to acknowledge this is an issue of concern. Their findings bear out the common complaint by users that we are not treated with respect, dignity or even common courtesy by many health workers, especially 